\title{
Assessment of the Tuscan Olive Germplasm by Microsatellite Markers Reveals Genetic Identities and Different Discrimination Capacity among and within Cultivars
}

\author{
Claudio Cantini ${ }^{1}$ and Antonio Cimato \\ Trees and Timber Institute, National Research Council, via Madonna del Piano, 10-50019 Sesto \\ Fiorentino (FI), Italy \\ Antonella Autino, Alessandro Redi, and Mauro Cresti \\ Dipartimento di Scienze Ambientali, Università degli Studi di Siena, Via P.A. Mattioli, \\ 4-53100 Siena, Italy
}

\begin{abstract}
AdDitional Index words. Olea europaea, genetic resources, molecular markers
Abstract. Microsatellite markers were used to characterize the accessions in the Tuscan olive (Olea europaea L.) germplasm collection. One hundred fifty-four genotypes were considered for genetic fingerprinting using 12 pairs of microsatellite primers. Investigation was focused on genotypes with similar morphologies and clones of the same cultivar from different agroecological areas within Tuscany. All 12 primer pairs produced microsatellite fragments for all the accessions amplifying from three to 10 alleles with a mean of 5.7 alleles/locus. The discovery of 30 synonyms and several misnames set the final number of genotypes representing the whole germplasm collection at 79 . For Frantoio, Leccino, and Pendolino, no intracultivar diversity was found, although Leccino was known to have morphological distinction. Heterozygosity levels for the loci ranged from 0.287 to 0.722 with a mean value of 0.524 . Some accessions presenting small differences in fingerprinting with similarity index greater than 0.87 were morphologically indistinguishable. The study demonstrates that for the management of the olive germplasm collection, it is necessary to use the morphological information in addition to the fingerprint when dealing with accessions presenting a microsatellite profile with high similarity index; otherwise, the risk is to overestimate the diversity among cultivars or presumed cultivars and to underestimate the one diversity already present within the cultivars.
\end{abstract}

Olive is one of the most ancient cultivated fruit trees and oilproducing crop of the Mediterranean basin with a very high historical and economical relevance, especially within the Italian peninsula where it also plays a fundamental role in landscape maintenance. Thanks to the long-living character of the tree and the low breeding pressure to which Olea L. species has been subjected, olive accounts for a very rich genetic patrimony. A survey of the Food and Agriculture Organization of the United Nations on published sources revealed the presence of more than 1200 cultivars worldwide, 476 of which are present in Italy with 1599 synonyms (Bartolini et al., 1998). Presently, correct identification of the olive accessions maintained in the several existing collections is hampered by the use of the same denomination for two or more different cultivars or genotypes (homonyms) and by the use of two or more different names for the same genotype (synonyms). Moreover, the exchange of olive propagation material among producing countries makes it easier for the different names of the same genotype (Belaj et al., 2000a). Another issue that complicates the identification is that most olive cultivars are made of groups of landraces sharing similar morphological features with large variation around the mean traits as a result of environmental factors (Gemas et al., 2004).

Received for publication 20 Mar. 2008. Accepted for publication 27 May 2008. ${ }^{1}$ Corresponding author. E-mail: cantini@ivalsa.cnr.it.
A reliable, unambiguous genetic identification of olive accessions is needed for biodiversity preservation programs as well as for nursery plant certification. The need for a method of DNA recognition spreads even to the olive oil industry where identification of the genotypes from which the oil has been extracted (Breton et al., 2004; Pasqualone et al., 2004) would allow a stricter certification of the final product.

In recent years, different kinds of markers have been successfully used in olive species. Random amplified polymorphic DNAs (RAPDs) and restriction fragment length polymorphism showed good discriminatory properties (Belaj et al., 2000b; Besnard et al., 2001; Fabbri et al., 1995; Gemas et al., 2000; Guerin et al., 2002; Mekuria et al., 1999; Sanz-Cortez et al., 2001). Amplified fragment length polymorphism (AFLPs) were also used for exploring germplasm (Angiolillo et al., 1999; Sensi et al., 2003). Recently also, single nucleotide polymorphism has been used to discriminate olive cultivars (Reale et al., 2006). Although these markers have resulted in the ability to discriminate among olive cultivars, their dominant character (RAPDs and AFLPs) or poor reproducibility among different laboratories and experiments (RAPDs) are still considered major drawbacks in cultivar fingerprinting. Among the others, microsatellite markers have proved successful for germplasm fingerprinting of woody plants. These markers exhibit a high level of polymorphism. In diversity studies, because of their codominant character, they are more effective than others in estimating heterozygosity. The capacity of 
microsatellite primers for evaluating genetic diversity between different genotypes is the first prerequisite for genetic characterization of germplasm collections. Furthermore, microsatellites seem to be suitable for such purpose as a result of their adaptability to high-throughput studies as well as adaptability for database setup.

Recently, several microsatellites have been isolated from olives (Carreiro et al., 2002; Cipriani et al., 2002; De La Rosa et al., 2002) and have been successfully used in olive cultivar identification (Bandelj et al., 2002; Cipriani et al., 2002; Rallo et al., 2000; Sefc et al., 2000) and germplasm characterization and management (Angiolillo et al., 2006; Bandelj et al., 2004; Khadari et al., 2003; Muzzalupo et al., 2006; Rotondi et al., 2003). Because microsatellites have demonstrated that they are the most suitable markers for genetic diversity evaluation in germplasm collections, they have been selected for fingerprinting a collection of olive genotypes representing the Tuscan olive germplasm.

In the present study, we tested whether microsatellite primers developed from cultivated olive would enable the complete fingerprinting of the Tuscan olive collection maintained by the National Research Council of Italy, which has never been previously characterized by molecular markers. We investigated whether the polymorphism displayed by DNA amplification with 12 different primer pairs would be sufficient to distinguish among all the genotypes, particularly those presenting very close morphological features, and to assess the possibility of homonyms or synonyms not discovered by the comparison of morphological characteristics. For our purpose, differently from most of the previous papers on the subject, intracultivar diversity was also investigated by introducing into the analysis several Leccino accessions known as somatic clones of the same genotypes according to their phenotype (Bartolini et al., 2003) as well as six and five accessions of Frantoio and Pendolino, respectively, from different agroecological areas (AEAs) within Tuscany. For another 25 different denominations, two to five accessions, collected in different AEAs were also screened to verify genotypic identity and the presence of intracultivar diversity.

\section{Materials and Methods}

One hundred fifty-four accessions of Tuscan olive germplasm kept in the National Research Council of Italy collection at the Santa Paolina experimental farm in Follonica, Italy, were available for genetic fingerprinting. Each accession was represented in the collection by four trees coming from a single mother plant. All the accessions included in the fingerprinting program and listed in Table 1 were already characterized by traditional methods as partially reported in Cantini et al. (1999), and their morphological traits were confirmed by more than 5 years of observation. The 154 accessions in the list were known by 102 different names, besides which there were two accessions with unknown names.

DNA EXTRACTION AND AMPLification. Young leaves of the 154 accessions of $O$. europaea were removed from the tip of the annual vegetative shoots. The leaves collected from the four plants of each genotype were pooled and then immediately frozen in liquid nitrogen. A total of $100 \mathrm{mg}$ of each sample was ground into a fine powder using a mortar and pestle under liquid nitrogen. Total genomic DNA was extracted using Nucleon Phytopure (GE Healthcare Life Sciences, Little Chalfont, UK)
Table 1. List of names and number of accessions with the same name belonging to the Tuscan olive germplasm collection scored by microsatellites.

\begin{tabular}{|c|c|c|c|}
\hline Name & $\begin{array}{l}\text { Accessions } \\
\text { (no.) }\end{array}$ & Name & $\begin{array}{l}\text { Accessions } \\
\text { (no.) }\end{array}$ \\
\hline Albatro & 2 & Morcone & 3 \\
\hline Allora & 2 & Morello a punta & 1 \\
\hline Americano & 1 & Mortellino & 1 \\
\hline Arancino & 1 & $\begin{array}{l}\text { Olivastra di } \\
\text { Populonia }\end{array}$ & 1 \\
\hline Brucolo & 1 & $\begin{array}{c}\text { Olivastra di } \\
\text { Suvereto }\end{array}$ & 1 \\
\hline Ciliegino & 1 & Olivo bufalo & 1 \\
\hline Colombana & 1 & Olivo del Mulino & 1 \\
\hline Colombino & 2 & Olivo del Palone & 1 \\
\hline Correggiolo & 2 & Olivo del Priore & 1 \\
\hline Cucca & 2 & Olivo della Strega & 1 \\
\hline Cuoricino & 2 & Olivo di Casavecchia & 1 \\
\hline Da Cuccare & 1 & Olivo di Cerreto & 1 \\
\hline Emilia & 1 & Olivo di San Lorenzo & 1 \\
\hline Filare & 1 & Olivo Forestiero & 1 \\
\hline Fiorentino & 1 & Olivone & 1 \\
\hline Firenzuolo & 1 & Ornellaia & 1 \\
\hline $\begin{array}{l}\text { Frantoiano di } \\
\text { Montemurlo }\end{array}$ & 1 & Pendagliolo & 2 \\
\hline Frantoio & 6 & Pendolino & 5 \\
\hline Ginestrino & 1 & Piangente & 2 \\
\hline Giogolino & 1 & Pignolo & 1 \\
\hline Grappolo & 2 & Piturzello & 1 \\
\hline Gremigna Tonda & 1 & Punteruolo & 1 \\
\hline Gremigno di Fauglia & 1 & Puntino & 1 \\
\hline Gremigno di Montecatini & 1 & Quercetana & 1 \\
\hline Gremignolo & 1 & Rama Pendula & 1 \\
\hline Gremignolo di Bolgheri & 1 & Razzaio & 1 \\
\hline Grossaio & 1 & Razzo & 2 \\
\hline Grossolana & 1 & Razzola & 1 \\
\hline Larcianese & 1 & Rosino & 3 \\
\hline Lastrino & 1 & Rossellino & 2 \\
\hline Lazzera Reale & 1 & $\begin{array}{l}\text { Rossellino } \\
\text { Cerretano }\end{array}$ & 1 \\
\hline Lazzera Vallescaja & 1 & Rossello & 1 \\
\hline Lazzero & 1 & Rossino & 2 \\
\hline Lazzero di Prata & 1 & S. Ilario & 1 \\
\hline $\begin{array}{l}\text { Lazzero della } \\
\text { Guadalupe }\end{array}$ & 1 & Salicino & 1 \\
\hline Lazzero Pratigiano & 1 & San Donato & 1 \\
\hline Leccino & 8 & San Francesco & 1 \\
\hline Leccio del Corno & 4 & San Lazzero & 1 \\
\hline Leccio Maremmano & 1 & Santa Caterina & 1 \\
\hline Leccione & 1 & Scarlinese & 1 \\
\hline Madonna dell'Impruneta & 2 & Scergolo & 1 \\
\hline Madremignola & 1 & Seggianese & 5 \\
\hline Maremmano & 2 & Selvatica Tardiva & 1 \\
\hline Marzio & 2 & Striscione & 1 \\
\hline Maurino & 3 & Tisignana & 1 \\
\hline Melaiolo & 1 & Tondello & 1 \\
\hline Mignolo & 2 & Tondino & 1 \\
\hline Mignolo Cerretano & 2 & Trillo & 1 \\
\hline Moraiolo & 3 & Ulivello & 1 \\
\hline Morcaio & 2 & Urano $^{\circledR}$ & 1 \\
\hline Morchiaio & 2 & Unknown & 2 \\
\hline
\end{tabular}


according to the manufacturer's specifications. Each genotype was collected and DNA was extracted at least twice to produce two different sets of DNA to be amplified separately.

To conduct the genetic characterization, 39 olive-specific microsatellite primer pairs were constructed using DNA sequences from different sources. Nine of these were designed from microsatellite sequences (AJ279853, AJ279854, AJ279855, AJ279856, AJ279857, AJ279858, AJ279860, AJ279865, AJ279867) published in GeneBank (Sefc et al., 2000) and named series SIU. Designing of primers was performed using the program Primer 0.5 (provided by S. Lincoln, M. Daly, and E. Lander). The other 30 primer pairs were constructed as reported in Cipriani et al. (2002; series UDO). All 39 pairs of primers were preliminarily screened, amplifying olive genomic DNA to individuate the best annealing temperature, number and length of resulting amplified fragments, reproducibility, and ease of scoring. Amplified products were then analyzed by electrophoresis in 3\% MetaPhor ${ }^{\mathrm{TM}}$ (FMC BioProducts, Philadelphia, PA) agarose gel and stained with ethidium bromide so as to verify the primer capability to identify length polymorphisms.

The set of 12 pairs of primers used in fingerprinting (Table 2) were selected because of their similar features: 19 to 27 base pairs (bp) in length; required annealing temperatures between 57 and $65.5^{\circ} \mathrm{C}$; the maximum number of amplified fragments were limited to two as expected from the olive diploid genome; and the length of the amplified fragment ranged from 99 to $208 \mathrm{bp}$.

All the polymerase chain reactions (PCRs) with the DNA extracted from the accessions were performed on a Mastercycler Gradient (Eppendorf AG, Hamburg, Germany) in $25 \mu \mathrm{L}$

Table 2. Name of the locus, sequence, and length in base pairs (bp) of the 12 microsatellite primer pairs used to fingerprint 154 diploid olive accessions collected within the Tuscany region.

\begin{tabular}{llc}
\hline Locus & \multicolumn{1}{c}{ Primer } & $\begin{array}{c}\text { Length } \\
\text { (bp) }\end{array}$ \\
\hline UDO04 & TTTGCCCTGGATTGGTACA & 19 \\
& AGCTTGAGCATCATCTGTGAG & 21 \\
UDO06 & TCAGTTTGTTGCCTTTAGTGGA & 22 \\
& TTGTAATATGCCATGTAACTCGAT & 24 \\
UDO09 & TTGATTTCACATTGCTGACCA & 21 \\
& CATAGCGAAGAGCTGCAAGG & 20 \\
UDO11 & TGACTCCCTTTAAACTCATCAGC & 23 \\
& TGCGCATGTAGATGTGAATATG & 22 \\
UDO12 & TCACCATTCTTAACTTCACACCA & 23 \\
& TCAAGCAATTCCACGCTATG & 20 \\
UDO17 & GCCCACAAACTCTTTGAACC & 20 \\
& GCGATTTTTCCCTGTATTTAGGT & 23 \\
UDO19 & TCCCTTGTAGCCTCGTCTTG & 20 \\
& GGCCTGATCATCGATACCTC & 20 \\
UDO24 & GGATTTATTAAAAGCAAAACATACAAA & 27 \\
& TTGATGACTAGCACACATGTAGGA & 26 \\
UDO27 & TCCGTGCAAACCATGAAATA & 20 \\
& TTGATGACTAGCACACATGTAGGA & 24 \\
UDO31 & TATCCTCTATGTGGCGATG & 19 \\
& TTGGTTAAAAGGATTGATACA & 21 \\
SIU06 & CCAACACTGACCGTTTCTTT & 20 \\
& ATTCAACCTCACCCCCATAC & 20 \\
& CCCATACGAACTGCCACTAA & 20 \\
& TCGTGTTGCTGTGAAGAAAA & 20 \\
\hline
\end{tabular}

volume containing $25 \mathrm{ng}$ of olive genomic DNA, $0.4 \mu \mathrm{M}$ of each primer, $200 \mu \mathrm{M}$ of dNTPs, $1 \times$ Taq reaction buffer $(500 \mathrm{mM} \mathrm{KCl}$, $100 \mathrm{~mm}$ Tris- $\mathrm{HCl}, \mathrm{pH} 9.0$, at $\left.25^{\circ} \mathrm{C}, 1.5 \mathrm{~mm} \mathrm{MgCl}_{2}\right)($ Amersham Pharmacia, Little Chalfont, UK), and 0.2 units of Taq DNA polymerase (Eppendorf AG). All the forward primers of each couple were labeled with Cy5 dye to allow detection of the amplified DNA.

Cycling conditions were the same for all loci. Initially, DNA was denatured for $5 \mathrm{~min}$ at $94^{\circ} \mathrm{C}$ followed by 30 cycles of $94^{\circ} \mathrm{C}$ for $45 \mathrm{~s}, 65.5$ to $57.8^{\circ} \mathrm{C}$ in relation to the used primer pairs for $45 \mathrm{~s}$, and $72{ }^{\circ} \mathrm{C}$ for $45 \mathrm{~s}$. A final 8 -min extension at $72{ }^{\circ} \mathrm{C}$ was included.

To obtain more precise estimates of fragment sizes and to identify even small differences in size between fragments, PCR products Cy5-labeled were electrophoresed on an AlfExpress ${ }^{\mathrm{TM}}$ Sequencer (Amersham Pharmacia). Sizing of the labeled fragments or alleles detected by the automated sequencer was performed using Allelelink software (Amersham Pharmacia). DNA amplification and sizing were repeated at least twice for each accession to ensure the most reliable results using commercial standards produced by Amersham Pharmacia as the internal sizing reference.

Data Analysis. Sizing statistics were performed to determine the number of alleles per locus, allele frequencies, expected (HE) and observed (HO) heterozygosity (Nei, 1978), and discrimination power (Jones, 1972; Kloosterman et al., 1993). The discrimination power is the probability that two diploid olive accessions can be distinguished by their microsatellite profiles. It is calculated as one minus the probability that the profiles will be identical (Jones, 1972). All the calculations were done using Identity freeware (version 1.0; Center for Applied Genetics, University of Agricultural Sciences, Vienna, Austria). The software NTSYSpc (Exeter Software, Setauket, NY) was used to calculate the genetic distance among accessions with the production of a similarity parameter based on the number of shared bands (Lynch, 1990). Sequential agglomerative hierarchical nested cluster analysis with unweighted pair group method of clustering (UPGMA) was successively applied and the tree plot procedure of the same package was finally used to provide a graphic representation of Lynch's similarity index data, from which relationships among accessions may be deduced.

\section{Results and Discussion}

Not more than two fragments were amplified for each primer pair in all the accessions. Because segregation data for the scored amplified fragments are not available, the fragments amplified represent putative loci and putative alleles. However, for simplicity, all primer pairs here are referred to as loci, and fragments generated by each primer pair in an amplification reaction are referred to as alleles. All the selected primer pairs gave a clear reproducible pattern of fragments amplification. Small differences in length ( 1 to $2 \mathrm{bp}$ ) among fragments at each locus were detected and confirmed by several rounds of PCR and scoring cycles. All 12 primer pairs produced microsatellite fragments for all the accessions amplifying from three to 10 alleles with a mean of 5.7 alleles/locus (Table 3 ).

The first aim of the work was to screen for possible homonyms/synonyms. To achieve this goal, the microsatellite profiles were combined over the 12 loci for all accessions and comparisons were made to identify any accessions that were 
Table 3. Microsatellite fragments ${ }^{\mathrm{z}}$ detected in 79 olive accessions belonging to the olive germplasm of Tuscany and their relative frequency (f).

\begin{tabular}{|c|c|c|c|c|c|c|c|c|c|c|c|}
\hline \multicolumn{2}{|c|}{ UDO04 } & \multicolumn{2}{|c|}{ UDO06 } & \multicolumn{2}{|c|}{ UDO09 } & \multicolumn{2}{|c|}{ UDO11 } & \multicolumn{2}{|c|}{ UDO12 } & \multicolumn{2}{|c|}{ UDO17 } \\
\hline (bp) & (f) & (bp) & (f) & (bp) & (f) & $\overline{(b p)}$ & (f) & (bp) & (f) & $\overline{(b p)}$ & (f) \\
\hline 144 & 0.538 & 150 & 0.424 & 99 & 0.399 & 103 & 0.063 & 157 & 0.323 & 156 & 0.107 \\
\hline 146 & 0.019 & 163 & 0.032 & 101 & 0.101 & 106 & 0.013 & 159 & 0.127 & 159 & 0.304 \\
\hline \multirow[t]{8}{*}{148} & 0.443 & 167 & 0.044 & 103 & 0.253 & 110 & 0.076 & 164 & 0.171 & 161 & 0.114 \\
\hline & & 169 & 0.076 & 107 & 0.006 & 112 & 0.209 & 166 & 0.380 & 163 & 0.025 \\
\hline & & 172 & 0.341 & 117 & 0.241 & 114 & 0.114 & & & 165 & 0.297 \\
\hline & & 174 & 0.357 & & & 116 & 0.063 & & & 169 & 0.013 \\
\hline & & 183 & 0.019 & & & 122 & 0.203 & & & 173 & 0.139 \\
\hline & & & & & & 124 & 0.089 & & & & \\
\hline & & & & & & 129 & 0.158 & & & & \\
\hline & & & & & & 133 & 0.013 & & & & \\
\hline \multicolumn{2}{|c|}{ UDO19 } & \multicolumn{2}{|c|}{ UDO24 } & \multicolumn{2}{|c|}{ UDO27 } & \multicolumn{2}{|c|}{ UDO31 } & \multicolumn{2}{|c|}{ SIU06 } & \multicolumn{2}{|c|}{ SIU08 } \\
\hline (bp) & (f) & (bp) & (f) & (bp) & (f) & (bp) & (f) & (bp) & (f) & (bp) & (f) \\
\hline 100 & 0.013 & 167 & 0.108 & 112 & 0.019 & 110 & 0.259 & 154 & 0.076 & 188 & 0.032 \\
\hline 102 & 0.089 & 172 & 0.101 & 121 & 0.297 & 114 & 0.089 & 160 & 0.120 & 192 & 0.177 \\
\hline 132 & 0.734 & 179 & 0.127 & 194 & 0.582 & 117 & 0.006 & 162 & 0.044 & 194 & 0.019 \\
\hline 165 & 0.006 & 181 & 0.152 & 199 & 0.101 & 128 & 0.006 & 164 & 0.032 & 199 & 0.595 \\
\hline \multirow[t]{5}{*}{171} & 0.158 & 184 & 0.063 & & & 139 & 0.146 & 166 & 0.209 & 201 & 0.152 \\
\hline & & 186 & 0.443 & & & 141 & 0.120 & 168 & 0.127 & 206 & 0.006 \\
\hline & & 192 & 0.006 & & & 145 & 0.089 & 170 & 0.310 & 208 & 0.019 \\
\hline & & & & & & 147 & 0.025 & 177 & 0.076 & & \\
\hline & & & & & & 149 & 0.254 & 183 & 0.006 & & \\
\hline
\end{tabular}

${ }^{\mathrm{z}}$ Microsatellite fragments are identified by their length in base pairs (bp).

the more asymmetric shape of its fruits. The phenotypic data collected from young plants in the collection of Frantoio and Correggiolo did not show this difference, because it appears evident only in the old mother plant.

Other than misnaming, the fingerprinting led to the discovery of the use of the same name for dissimilar plants (homonymy) as happened for the denominations Cucca, Morcaio, and Rossino. For these three couples, we had six different fingerprints, none of them identical to any other, thus confirming the differences within each of the three couples already found by morphological analysis. A last misnaming was found in Pendagliolo, which was represented in the collection by two accessions, one of which was instead identical to Frantoio. None of the two unknown accessions shared its microsatellite profile with any of the named cultivars and they are genotypes that remain unidentified.

Intracultivar analyses also were informative, especially that of Frantoio and Leccino. These are two of the most important Tuscan cultivars and are

scored as genetically identical. The fingerprinting data were always combined with the phenotypic data when any discrepancy was found, for example, different fingerprinting for accessions with identical names. The phenotypic data were also controlled for all the accessions with identical fingerprinting.

From this analysis, 30 accessions were identified that had a fingerprint identical to another accession with a different name (synonymy), and this was not discovered in the past by phenotyping because several characters were scored differently. Using the fingerprints, we were able to select the accessions that had identical fingerprints, analyze all the information, including photographs and samples of fruits and pits, and, where necessary, correct the data. In most cases, the accession, entered in the collection with a local name, corresponded to a well-known genotype. For example, the accessions Madonna di Impruneta, Gremigno di Montecatini, Morcone, and Olivo del Palone had a fingerprint identical to that of Leccino. Other misnames were found for Filare, Pignolo, Piturzello, and Trillo, which are all used for the Tuscan genotype Moraiolo; Firenzuolo used for Americano; Frantoiano di Montemurlo for Grossaio; and Ginestrino for Maurino. The three names, Lazzera reale, Lazzera di Vallescaja, and Morello a punta, were used for the genotype Lazzero; Olivo del Priore for Morcone; Olivo di San Lorenzo for Marzio; and Razzaio for Lazzero Guadalupe. Six accessions had a fingerprint identical to that of the Frantoio and were known in the different AEAs as Correggiolo, Larcianese, Olivo della Strega, Rama pendula, Razzo, and San Lazzaro. The name Correggiolo traditionally is used as a synonym of Frantoio, although in some areas, they are not considered the same. A distinctive phenotypic character used to distinguish Correggiolo from Frantoio is its long, growing-toward-the-soil, fruiting shoot-in the old Tuscan idiom, correggiolo is the word for a leather string - and exported and used in almost all olive-producing countries. The fingerprinting of the six accessions of Frantoio as well as the eight of Leccino and the five of Pendolino collected in different AEAs did not show any intracultivar diversity. For Frantoio and Pendolino, this lack of differences in the genotype confirmed the identical morphological characters, whereas the accessions of Leccino presented different agronomical features. In particular, one of Leccino was selected and registered by the Italian cultivar registry for its self-compatibility, which is uncommon because the cultivar is generally known as selfincompatible.

After this initial elimination of the misnames or synonyms, we were able to identify a set of 79 genotypes that represent the whole olive autochthonous germplasm of Tuscany. Genetic distance (Lynch, 1990) was then used to produce a phenogram based on the UPGMA method of clustering (Fig. 1), in which only the three couples of denominations, namely Rossino, Cucca, and Morcaio, are presented twice. The germplasm characterization produced a complete list of fragments per locus as shown in Table 3; $38 \%$ of the alleles belonged to the two lowest frequency classes, whereas $30 \%$ of the alleles had frequency values greater than 0.2 (Table 4). The number of alleles for each locus determined by our group (three to 10 ; average, 5.7) was lower compared with other woody species (Hokanson et al., 1998; Lavi et al., 1994; Thomas and Scott, 1993). Our numbers were also lower than previously reported in olive using microsatellites (Khadari et al., 2003; Muzzalupo et al., 2006; Rallo et al., 2000; Sefc et al., 2000). The number of alleles found in the plants of Tuscany could be explained by the strictly local provenience of the germplasm we investigated.

Accessions with only a single amplified fragment were assumed to be homozygous for that fragment for purposes of computing heterozygosity and gene diversity. However, if null 


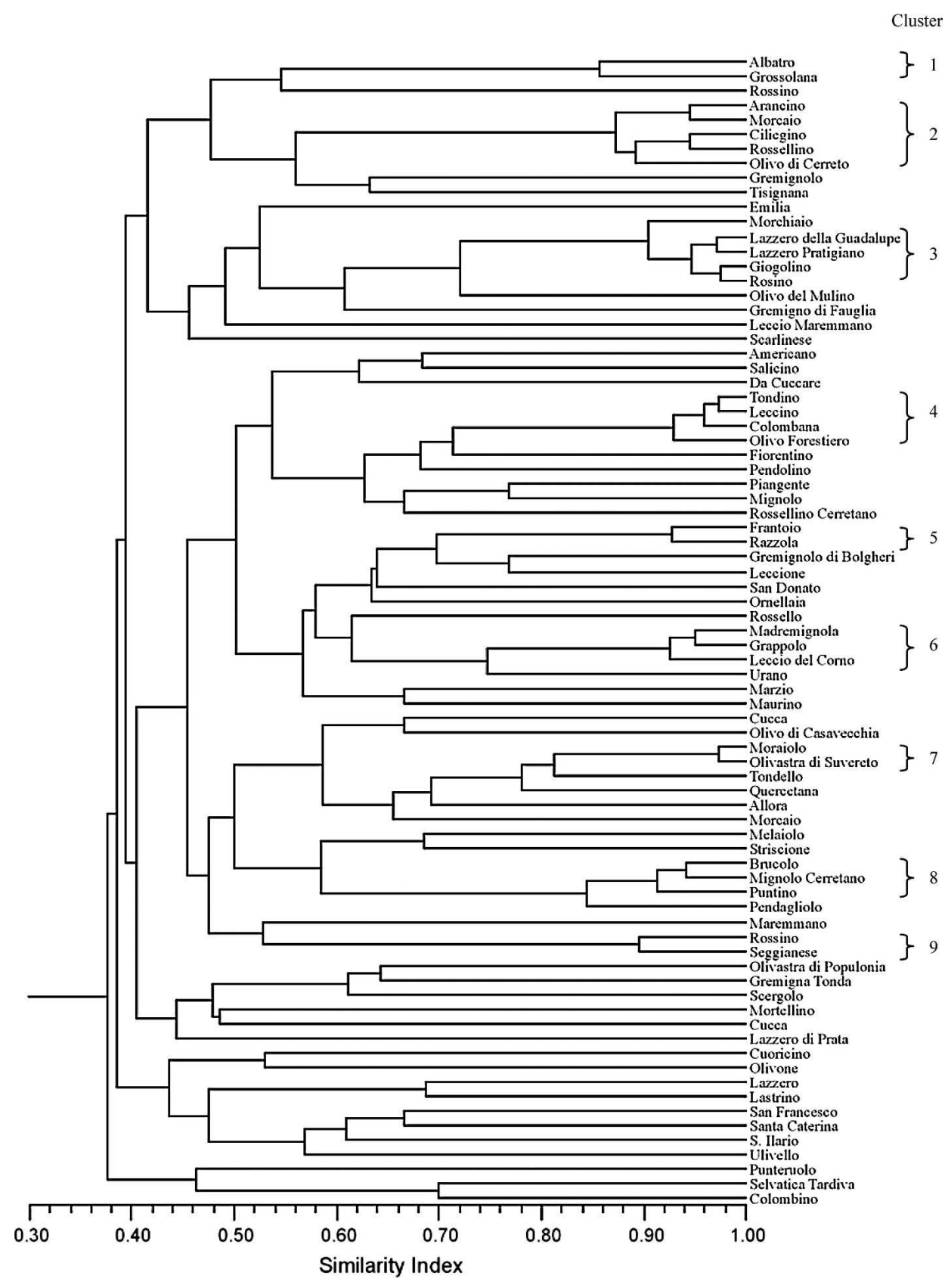

Fig. 1. Dendrogram of the 79 genotypes representing the olive germplasm of Tuscany generated by unweighted pair group cluster analysis (UPGMA) based on Lynch's (1990) genetic distance. The nine clusters indicated with Arabic numbers represent groups of cultivars with identical morphological features. alleles are present in the population, this leads to an underestimate of the percentage of heterozygosity. Heterozygosity levels for the loci identified by each primer pair ranged from 0.278 to 0.722 with a mean value of 0.524 (Table 5). HE ranged from 0.514 to 0.855 with a mean value of 0.688 . The average level of polymorphism detected in the Tuscan population $(\mathrm{HO}=0.524)$ is lower than that detected with microsatellites in a recent study made on Italian $(\mathrm{HO}=0.778)$ and Iberian $(\mathrm{HO}=0.653)$ olive trees (Sefc et al., 2000). These differences could be related to the number of observations, which was limited to nine and 38 accessions, respectively, from Italy and from the Iberian Peninsula. Level of expected heterozygosity calculated in our sample $(\mathrm{HE}=$ 0.688) was lower than that determined by Sefc et al. (2000) for the nine Italian accessions $(\mathrm{HE}=0.751)$ but close to the total of the two combined populations (0.693) and similar to that determined by Muzzalupo et al. (2006) after sequencing simple sequence repeat loci of the Apulian germplasm collection (HE $=0.66$ ). The primer pair giving more information based on discrimination power and the probability of matching genotype fingerprinting was UDO11, whereas the less informative was UDO04. Some of the loci with a low number of possible alleles and larger difference in fragments size were easier to score but gave less information and lower discrimination power. Among them, UDO27 presented the best combination of low number of alleles and high power of discrimination. UDO17 and especially UDO09 increased the separation among fingerprints. Six of 10 accessions that differed by only one locus were differentiated by products generated using the UDO09 primers.

After the production of the dendrogram with the 79 unique genotype profiles in Figure 1, we noticed that some groups of accessions presented a very high similarity index. The first two genotypes at the top of Figure 1, named Albatro and Grossolana, differed for only two bases at locus UDO17 where both had a single band. These were $165 \mathrm{bp}$ in Albatro and $163 \mathrm{bp}$ in Grossolana. The same was true at locus SIU8 with values, respectively, of 199 and 201. The existence of the alleles with 2-bp difference was confirmed by several replicates. However, the plants did not show any phenotypic or agronomic difference. Observing the clustering in Figure 1, it can be noticed that nine groups of two to five accessions present a Lynch's 
Table 5. Observed (HO) and expected (HE) heterozygosity, probability of two fingerprints matching by chance, and discrimination power at each locus as resulting from the fingerprinting of the olive germplasm of Tuscany by 12 microsatellite markers.

\begin{tabular}{lcccc}
\hline Locus & $\mathrm{HO}^{\mathrm{z}}$ & $\mathrm{HE}^{\mathrm{z}}$ & $\begin{array}{c}\text { Probability of } \\
\text { identity }^{\mathrm{z}}\end{array}$ & $\begin{array}{c}\text { Discrimination } \\
\text { power }^{\mathrm{z}, \mathrm{y}}\end{array}$ \\
\hline UDO04 & 0.418 & 0.514 & 0.587 & 0.413 \\
UDO06 & 0.468 & 0.695 & 0.238 & 0.762 \\
UDO09 & 0.608 & 0.709 & 0.241 & 0.759 \\
UDO11 & 0.696 & 0.855 & 0.070 & 0.930 \\
UDO12 & 0.582 & 0.706 & 0.247 & 0.753 \\
UDO17 & 0.468 & 0.779 & 0.145 & 0.855 \\
UDO19 & 0.418 & 0.428 & 0.436 & 0.564 \\
UDO24 & 0.557 & 0.760 & 0.136 & 0.864 \\
UDO27 & 0.570 & 0.562 & 0.399 & 0.601 \\
UDO31 & 0.722 & 0.827 & 0.094 & 0.906 \\
SIU06 & 0.278 & 0.815 & 0.102 & 0.898 \\
SIU08 & 0.506 & 0.605 & 0.276 & 0.724 \\
Mean & 0.524 & 0.688 & - & - \\
All loci & - & - & $5.18 \times 10^{-9}$ & $\approx 1$
\end{tabular}

${ }^{\mathrm{z}}$ Values were rounded to three significant digits after computation. ${ }^{\mathrm{y}}$ Discrimination power is one minus the probability of a matching fingerprint.

similarity index higher than 0.87 . We concentrated our attention on these groups, considering the value of 0.87 as just an arbitrary tool for germplasm screening, again checking all the genotyping and morphological data and, where necessary, also directly the plants in collection. We subsequently discovered that several of the accessions presenting small differences in the fingerprint were morphologically indistinguishable. The accessions that can be grouped under the same phenotype despite the different fingerprinting are shown as components of nine different clusters in Figure 1. Our work is focusing on deep characterization of these groups of plants to clarify whether the components are presenting physiological or phenotypical variations from the main cultivar of each cluster.

The clustering also enabled us to clarify the position of two accessions in collection with the denominations of Morcaio and Rossino. One accession of each couple was introduced in collection with an erroneous name because they shared morphological attributes, respectively, with Arancino and Seggianese. There remains in the collection now only one homonymy for Cucca with two accessions characterized by different genotypes and phenotypes.

Characterization of synonyms, elimination of redundancy, and maximization of genetic diversity are main goals in olive germplasm collections. So far, efforts have been made worldwide using molecular markers as microsatellites because they are usually considered reliable and reproducible among different laboratories. However, the fingerprinting of the Tuscan germplasm, although collected in a very limited geographical area, proved to be very challenging. Our work showed that microsatellites do represent a good method for screening within collections and for confirming olive identities, although, without the coupled analysis of genotyping and morphological data, it would have been impossible to resolve the identity of each accession.

Muzzalupo et al. (2006) underlined the importance of DNA sequencing of the amplicons to reveal polymorphisms in microsatellite repeats because some alleles can have equal length but different repeating units. Nevertheless, we found that in some cases, a 2-bp difference in the length of the amplicons cannot be associated with any evident agronomical difference among olives, and so the consideration of the sole fingerprinting can lead to overestimation of the practical useful diversity. On the other hand, as shown by the analysis of Leccino accessions, an identical fingerprint obtained by microsatellites on the base of the size of the bands can also lead to underestimation of the diversity within an olive cultivar.

When dealing with a large number of accessions, the results of 12 microsatellite loci were sufficient, without sequencing, to identify common olive cultivars, to avoid genotype redundancy, and to maximize genetic diversity. Nevertheless, with this work, we have proven that for the management of an olive germplasm collection, it is necessary to use the morphological information in addition to the fingerprint, especially when dealing with accessions presenting a microsatellite profile with a high similarity index.

\section{Literature Cited}

Angiolillo, A., M. Mencuccini, and L. Baldoni. 1999. Olive genetic diversity assessed using amplified fragment length polymorphisms. Theor. Appl. Genet. 98:411-421.

Angiolillo, A., S. Reale, F. Pilla, and L. Baldoni. 2006. Molecular analysis of olive cultivars in the Molise region of Italy. Genet. Resour. Crop Evol. 53:289-295.

Bandelj, D., J. Jakše, and B. Javornik. 2002. DNA fingerprinting of olive varieties by microsatellite markers. Food Technol. Biotechnol. 40:185-190.

Bandelj, D., J. Jakše, and B. Javornik. 2004. Assessment of genetic variability of olive varieties by microsatellite and AFLP markers. Euphytica 136:93-102.

Bartolini, G., G. Prevost, C. Messeri, and G. Carignani. 1998. Olive germplasm cultivars and world-wide collections. Food and Agriculture Organization of the United Nations, Plant Production and Protection Division, Rome, Italy.

Bartolini, S., C. Cantini, and R. Guerriero. 2003. Prova comparativa di alcuni cloni di Leccino nella Maremma Toscana. Atti convegno germoplasma olivicolo e tipicità dell'olio. Perugia, p. 22-26.

Belaj, A., I. Trujillo, and P. Rallo. 2000a. Are 'Oblonga' and 'Frantoio' olives the same cultivar? HortScience 35:1323-1325.

Belaj, A., I. Trujillo, R. De La Rosa, and P. Rallo. 2000b. Polymorphism and discrimination capacity of randomly amplified polymorphic markers in an olive germplasm bank. J. Amer. Soc. Hort. Sci. 126:64-71.

Besnard, G., C. Breton, P. Baradat, B. Khadari, and A. Bervillé. 2001. Cultivar identification in olive based on RAPD markers. J. Amer. Soc. Hort. Sci. 126:663-675.

Breton, C., D. Claux, I. Metton, G. Skorski, and B. Bervillé. 2004. Comparative study of method for DNA preparation from olive oil samples to identify cultivar SSR alleles in commercial oil samples: Possible forensic applications. J. Agr. Food Chem. 52:531-537.

Cantini, C., A. Cimato, and G. Sani. 1999. Morphological evaluation of olive germplasm present in Tuscany region. Euphytica 109:173181

Carreiro, F., G. Fontanazza, F. Cellini, and G. Giorio. 2002. Identification of simple sequence repeats (SSRs) in olive (Olea europea L.). Theor. Appl. Genet. 104:301-307.

Cipriani, G., M.T. Marrazzo, R. Marconi, A. Cimato, and R. Testolin. 2002. Microsatellite markers isolated in olive (Olea europaea L.) are suitable for individual fingerprinting and reveal polymorphism within ancient cultivars. Theor. Appl. Genet. 104:223-228.

De La Rosa, R., C.M. James, and K.R. Tobutt. 2002. Isolation and characterization of polymorphic microsatellites in olive (Olea europaea L.) and their transferability to other genera in Oleaceae. Mol. Ecol. Notes 2:265-267. 
Fabbri, A., J.I. Hormaza, and V.S. Polito. 1995. Random amplified polymorphic DNA analysis of olive (Olea europea L.) cultivars. J. Amer. Soc. Hort. Sci. 120:538-542.

Gemas, V.J.V., M.C. Almadanim, R. Tenreiro, A. Martins, and P. Fevereiro. 2004. Genetic diversity in the olive tree (Olea europaea L. subsp. europaea) cultivated in Portugal revealed by RAPD and ISSR markers. Genet. Resour. Crop Evol. 51:501-511.

Gemas, V.J.V., M.J. Rijo-Johansen, R. Tenreiro, and P. Fevereiro. 2000. Inter-and Intra-varietal analysis of three Olea europaea L. cultivars using the RAPD techniques. J. Hort. Sci. Biotechnol. 75:312-319.

Guerin, R.J., S.M. Sweeney, G.G. Collins, and M. Sedley. 2002. The development of a genetic database to identify olive cultivars. J. Amer. Soc. Hort. Sci. 127:977-983.

Hokanson, S.C., A.K. Szewc-Mcfadden, W.F. Lamboy, and J.R. McFerson. 1998. Microsatellite (SSR) markers reveal genetic identities, genetic diversity and relationships in a Malus $\times$ domestica Borkh. core subset collection. Theor. Appl. Genet. 97:671-683.

Jones, D.A. 1972. Blood samples: Probability of discrimination. J. Forensic Sci. Soc. 12:355-359.

Khadari, B., C. Breton, N. Moutier, J.P. Roger, G. Besnard, A. Bervillé, and F. Dosba. 2003. The use of molecular markers for germplasm management in a French olive collection. Theor. Appl. Genet. 106:521-529.

Kloosterman, A.D., B. Budowle, and P. Daselaar. 1993. PCR-amplification and detection of the human D1S80 VNTR locus. Intl. J. Legal Medicine 105:257-264.

Lavi, U., M. Akkaya, A. Bhagwat, E. Lahav, and P.B. Cregan. 1994. Methodology of generation and characteristics of simple sequence repeat DNA markers in avocado (Persea americana Mill.). Euphytica 80:171-177.

Lynch, M. 1990. The similarity index and DNA fingerprinting. Mol. Biol. Evol. 7:478-484.

Mekuria, G.T., G.G. Collins, and M. Sedgley. 1999. Genetic variability between different accession of some common commercial olive cultivars. J. Hort. Sci. Biotechnol. 74:309-314.
Muzzalupo, I., N. Lombardo, A. Musacchio, M.E. Noce, G. Pellegrino, E. Perri, and A. Sajjad. 2006. DNA sequence analysis of microsatellite markers enhance their efficiency for germplasm management in an Italian olive collection. J. Amer. Soc. Hort. Sci. 131:352359.

Nei, M. 1978. Estimation of average heterozygosity and genetic distance from a small number of individuals. Genetics 89:583590.

Pasqualone, A., C. Montemurro, F. Caponio, and A. Blanco. 2004. Identification of virgin olive oil from different cultivars by analysis of DNA microsatellites. J. Agr. Food Chem. 52:1068-1071.

Rallo, P., G. Dorado, and A. Martìn. 2000. Development of a simple sequence repeats (SSRs) in olive tree (Olea europea L.). Theor. Appl. Genet. 101:984-989.

Reale, S., S. Doveri, A. Díaz, A. Angiolillo, L. Lucentini, F. Pilla, A. Martín, P. Donini, and D. Lee. 2006. SNP-based markers for discriminating olive (Olea europaea L.) cultivars. Genome 49: 1193-1205.

Rotondi, A., M. Magli, C. Ricciolini, and L. Baldoni. 2003. Morphological and molecular analyses for the characterization of a group of Italian olive cultivars. Euphytica 132:129-137.

Sanz-Cortez, F., M.L. Badenes, S. Paz, A. Iniguez, and G. Llàcer. 2001. Molecular characterization of olive cultivars using RAPD markers. J. Amer. Soc. Hort. Sci. 126:7-12.

Sefc, K.M., M.S. Lopes, D. Mendonça, M. Rodriguez Dos Santos, M. Laimer Da Camara Machado, and A. Da Camara Machado. 2000. Identification of microsatellite loci in olive (Olea europaea) and their characterization in Italian and Iberian olive trees. Mol. Ecol. 9:1171-1173.

Sensi, E., R. Vignani, M. Scali, E. Masi, and M. Cresti. 2003. DNA fingerprinting and genetic relatedness among cultivated varieties of Olea europea L. estimated by AFLP analysis. Scientia Hort. 97: 379-388.

Thomas, M.R. and N.S. Scott. 1993. Microsatellites repeats in grapevine reveal DNA polymorphisms when analysed as sequencetagged sites (STSs). Theor. Appl. Genet. 86:958-990. 